\title{
O PRINCÍPIO DA COOPERAÇÃO JUDICIÁRIA DO NOVO CÓDIGO DE PROCESSO CIVIL: UMA ANÁLISE A PARTIR DA PROTEÇÃO AO TRABALHADOR FRENTE AO INSTITUTO DA RECUPERAÇÃO JUDICIAL THE PRINCIPLE OF JUDICIAL COOPERATION NEW CODE OF CIVIL PROCEDURE: AN ANALYSIS PROTECTION FROM THE WORKER FRONT OF THE INSTITUTE OF JUDICIAL RECOVERY
}

\author{
Patricia Fernandes Bega ${ }^{1}$ \\ Alexandre Magno Augusto Moreira ${ }^{2}$
}

\section{RESUMO}

O artigo tem por tema estudar o Princípio da Cooperação Judicial. O problema da pesquisa se concentra no conflito entre o instituto da recuperação judicial e a legislação trabalhista. A hipótese inicial de trabalho é que o princípio da proteção ao trabalhador e o instituto da Recuperação Judicial revelam embate, contradição e não cooperação. Desta maneira, o trabalho procura demonstrar que a regra processual da cooperação judicial trazida pelo Novo CPC é um instrumento de diálogo entre contradições materiais. Objetiva-se analisar o novo código de processo civil e a dificuldade de cooperar o inconciliável. O método utilizado foi o dedutivo

Palavras-chave: Novo código de processo civil, Princípio da cooperação judiciária, Proteção do trabalhador, Recuperação judicial, Preservação da empresa

\begin{abstract}
The article is subject to study the Principle of Judicial Cooperation. The problem of research focuses on the conflict between the institution of bankruptcy and labor laws. The initial hypothesis is that the principle of protection to workers and the Judicial Recovery Institute reveal clash, contradiction and non-cooperation. In this way, the work seeks to demonstrate that the procedural rule of judicial cooperation brought about by the new CPC is an instrument of dialogue between material contradictions. The objective is to analyze the new civil procedure code and the difficulty to cooperate the irreconcilable. The method used was deductive.
\end{abstract}

Keywords: New civil procedure code, Principle of judicial cooperation, Protection worker, Judicial recovery, Company preservation

\footnotetext{
${ }^{1}$ Mestrada em Direito Empresarial e Cidadania pelo Centro Universitário Curitiba - UNICURITIBA, Paraná, (Brasil). Professora pela União de Ensino do Sudoeste do Paraná - UNISEP e pela Universidade Paranaense UNIPAR, Paraná, (Brasil). E-mail: patriciabega @ gmail.com

2 Mestrado em Direito Processual e Cidadania pela Universidade Paranaense - UNIPAR, Paraná, (Brasil). Advogado Sócio Proprietário do Escritório Araújo \& Moreira Sociedade de Advogados, Paraná, (Brasil). E-mail: alexandremagno@unipar.br
} 


\section{INTRODUÇÃO}

$\mathrm{Na}$ linha do tempo da existência de determinada empresa, faz-se comum a ocorrência de dificuldades financeiras na gestão de suas atividades, nestas situações de iliquidez comercial, verifica-se que empregados, credores, fisco e acionistas encontram-se próximos de uma situação de difícil solvência de crédito.

Para suprir essa dificuldade, fora editada a lei $n^{\circ} 11.101 / 2005$ de forma a auxiliar a manutenção da atividade empresarial, do emprego, bem como o atendimento aos interesses dos demais credores. Busca-se, assim, que a empresa além de quitar seus débitos, avance no mercado negocial, tendo condições de concorrer com outras empresas do mesmo segmento e gerar lucros, promovendo a manutenção dos postos de trabalho.

O instituto da Recuperação Judicial, antiga concordata, apresenta uma função de mão dupla: ao passo que em uma das vias procura-se garantir os interesses privados da sociedade empresarial que passa momentaneamente por uma crise financeira, na medida em que traz um leque de procedimentos cujo escopo é garantir a sua reestruturação e, consequentemente, a preservação dos interesses comunitários, dentre eles a manutenção dos postos de trabalhador e a garantia do emprego; na outra via procura-se que a recuperação judicial se dê de forma sadia, na medida em que possibilita a qualificação da sua capacidade competitiva.

Para que isso ocorra, surge o plano de recuperação judicial, nesse projeto de reestruturação praticamente todos os setores da empresa sofrem reajustes para melhor adequá-la ao "renascimento". Dentre esses setores, um deles que sofre grande impacto e tensão é justamente a esfera dos direitos dos trabalhadores, nessa área os profissionais devem continuar desempenhando seu papel de forma apta e ao mesmo tempo sofrerem limitações salariais.

Todo esse prejuízo tanto da sociedade que está relacionada com a empresa, como dos próprios trabalhadores que atuam diretamente, serão os responsáveis pela oportunidade manutenção da empresa através da recuperação judicial, caso exista ainda nela liquidez e competitividade e capacidade de satisfação do direito de crédito dos credores. 
O tema tem sua importância devido ao conflito principiológico existente entre a mitigação de alguns princípios correlato ao Direito do Trabalho frente a valorização de outros princípios que redigiram e motivaram a criação da Lei de Recuperações Judiciais, em especial o princípio da preservação da empresa.

Justifica-se a importância do assunto, uma vez que a aplicação das limitações salariais dos trabalhadores previstas na referida lei, colida com máximas constitucionais, haja vista pelo fato que a relação de trabalho e o direito do emprego, podem ser considerados como normas de direitos humanos, fundamentais e sociais.

A relação que se estabelece nos pedidos de recuperação judicial estão diretamente ligados com a situação econômica do país, isso tudo ao observar o desenvolvimento de determinada nação. O desenvolvimento inicial desta temática ocorreu no ano de 2011, momento no qual, diferente da situação de crise vivida na contemporaneidade, discutia-se a temática no programa de Mestrado em Direito Empresarial e Cidadania.

A proposta de conciliar o Novo Código de Processo Civil com a recuperação judicial ocorreu dentro do Programa de Pós-graduação Lato Sensu em Direito Processual Civil com ênfase no novo CPC que os autores são docentes.

O presente trabalho encontra-se divido em três partes, na primeira delas procura-se estudar a relação material entre as normas de direito do Trabalho e Recuperação Judicial, demonstra a ausência de diálogo entre estes dois institutos, bem como o conflito desta relação.

No segundo capítulo procura-se estudar o princípio da Cooperação Judiciária inserido no Novo Código de Processo Civil e sua relação com os processos de recuperação judicial.

Por fim, no último capítulo será analisado o princípio da cooperação nacional como um instrumento congruente para a efetividade do processo, demonstrando a relação dependente entre regras de direito material, mesmo de temáticas diversas e a disposição trazida no Novo Código de Processo Civil. 
Objetiva-se, com o trabalho, colaborar para o fornecimento de elementos à pesquisa que tenham por objeto o estudo desse importante instrumento do Novo Código de Processo Civil, o qual merece destaque diante das recentes inovações trazidas pelo novo código e os antigos conflitos de nosso ordenamento.

O Trabalho procura por meio de releituras dos referenciais teóricos processualistas, trabalhistas e empresariais desenvolver o trabalho a partir do método dedutivo, partindo de uma premissa geral (maior) para uma específica (menor), dividindo o mesmo em três partes. O presente trabalho não procura apresentar conclusões peremptórias, haja vista que representa um estado de pesquisa em desenvolvimento com resultados parciais.

\section{PRINCÍPIO DA PROTEÇÃO AO TRABALHADOR $\quad$ E A RECUPERAÇÃO JUDICIAL}

Em momentos de crise o instituto da recuperação judicial tem crescimento e a discussão acerca da permanência da empresa vira assunto de interesse público. Assim, justifica-se o estudo para que este colabore como fonte de pesquisa e valorização do instituto da Recuperação Judicial promovendo o desenvolvimento do estudo sobre os conflitos gerados pela Lei $\mathrm{n}^{\circ}$. 11.101/2005, em especial sobre a mitigação dos direitos dos trabalhadores, no contexto de crise nacional vividos na atualidade.

Percebe-se que as notícias acima foram retiradas de momentos de crescimento econômico, diversos da contemporaneidade, neste sentido, o estudo na contemporaneidade com as inovações trazidas pelo Novo Código de Processo Civil renascem.

O presente escrito não visa apenas ilustrar ou valorizar o instituto da Recuperação Judicial frente aos direitos dos empregados, mas sim demonstrar um viés amplo que mostra as consequências no mercado diante da decretação da falência de determinada sociedade empresarial. Desta maneira, não se procura negar direitos trabalhistas, mas valorizá-los, mesmo que o trabalho se dê de maneira contraditória, ou seja, ofendendo para depois tutelálos. 
A Lei $n^{\circ} .11 .101 / 2005$ que trouxe a Recuperação Judicial é valorada pelo princípio da preservação da empresa, o princípio da função social, o princípio da participação ativa dos credores e o princípio da proteção dos trabalhadores conforme previsão do Art. $47^{1}$ da mencionada lei.

Para que se possa compreender a finalidade desse instituto frente ao princípio da proteção do trabalhador, faz-se necessário conhecer o Princípio da Preservação da Empresa, o qual, conforme DOMINGOS (2009, p.78) representa Um princípio que estaria num plano superior, contudo "[...] o princípio em apreço jamais atingiria seu escopo se caminhasse solitário como um andarilho pela estrada árdua e tenebrosa que o empresário ou a sociedade empresária em situação econômico- financeira precária peregrinam.”

Embora a hierarquia de princípios seja matéria controvertida é possível afirmar que o princípio da preservação da empresa está intimamente ligado ao núcleo e a essência da Recuperação Judicial.

O princípio trabalha a ideia de uma cadeia alimentar de subsistência, na qual a retira da empresa pela falência provoca, como que em um efeito dominó, a insolvência de outros membros ligados a ela, em especial os direitos dos próprios trabalhadores.

Ressalta-se, que o trabalhador ao conquistar uma vaga de emprego, amparado pela perspectiva de crescimento pessoal, cria planos para sua família visando seu crescimento dentro de determinada empresa. Desta forma, o trabalhador acaba adquirindo débitos a longo prazo, como é o caso da aquisição casa própria e do incentivo estudantil superior, amparado pelas recentes políticas de liberação de crédito vividas em nosso país.

Além desses empregados ligados diretamente, outras empresas ligadas ao setor, como, por exemplo, os fornecedores, distribuidores e varejo contratam mais empregados para abastecer o mercado e, esses trabalhadores ligados indiretamente também visam um crescimento pessoal e adquirem bens e contraem dívidas, incentivados pelos planos de liberação de crédito do governo.

\footnotetext{
${ }^{3}$ Art. 47. A recuperação judicial tem por objetivo viabilizar a superação da situação de crise econômicofinanceira do devedor, a fim de permitir a manutenção da fonte produtora, do emprego dos trabalhadores e dos interesses dos credores, promovendo, assim, a preservação da empresa, sua função social e o estímulo à atividade econômica.
} 
Assim, nasce uma cadeia formada pela empresa, Trabalhador, Acionista, Fisco, Fornecedor, empregados do fornecedor, Varejo, empregados do Varejo. Todos esses membros da cadeia tem como vetor de existência a empresa principal, a qual se retirada pode provocar inúmeras "falências" e "insolvências" das unidades as quais é responsável pela existência, demonstrando o interesse público sobre o capital privado.

Sobre o princípio da proteção dos trabalhadores, o seu conteúdo encontra- se caracterizado, a priori, pela continuidade da atividade desempenhada, propiciando que os postos de trabalho permaneçam aptos a serem abastecidos; e, a posteri, nas hipóteses de decretação de falência, pela prevalência que assume para a prestação de seus créditos (artigo 83, da Lei $11.101 / 2005)^{2}$.

Conforme disciplina o mencionado artigo acima, os trabalhadores nessa primeira fase, mesmo pertencendo a primeira classe na ordem de crédito, haja vista seu crivo alimentar, tem seu direito de crédito nesse primeiro momento limitado a 150 (cento e cinquenta salários mínimos). Esse limite é obedecido para que o patrimônio da empresa não seja solvido apenas pelos trabalhadores, proporcionando aos demais credores a oportunidade do direito de crédito, haja vista que outros credores, como os fornecedores e varejo, também possuem empregados que dependem da existência da determinada empresa para a manutenção de seus postos de trabalho, tutela-se a propriedade privada da empresa recuperanda em prol de um direito coletivo.

A limitação legal, não significa que irão receber apenas 150 (cento e cinquenta salário mínimos) do valor do crédito trabalhista, mas que esse valor será privilegiado, ao passo que o remanescente será incluído no polo dos credores quirografários.

\footnotetext{
4 Art. 83. A classificação dos créditos na falência obedece à seguinte ordem: I - os créditos derivados da legislação do trabalho, limitados a 150 (cento e cinquenta) salários-mínimos por credor, e os decorrentes de acidentes de trabalho; II - créditos com garantia real até o limite do valor do bem gravado (...).

5 Art. 11 - 1. Em caso de falência ou de liquidação judiciária de uma empresa, os trabalhadores seus empregados serão tratados como credores privilegiados, seja pelos salários, que lhes são devidos a título de serviços prestados no decorrer de período anterior à falência ou à liquidação e que será prescrito pela legislação nacional, seja pelos salários que não ultrapassem limite prescrito pela legislação nacional.
} 
Nota-se, porém que o mencionado artigo colide diretamente com a previsão disposta no Art. 449, $\S 1^{\circ}$ da CLT "Na falência constituirão créditos privilegiados a totalidade dos salários devidos ao empregado e a totalidade das indenizações a que tiver direito". Porém, a Jurisprudência e a Doutrina têm entendido que tal disposição prevista na CLT foi revogada pelo Artigo da lei falimentar, conforme disposto na Convenção $95^{3}$ da Organização Internacional do Trabalho. Neste sentido,

[...] embora o artigo 449 da CLT tenha sido revogado, é demonstrado no texto infraconstitucional de princípios constitucionais, com a obrigatoriedade de subsistência de todos os direitos dos Trabalhadores. Segundo Del Masso "é assim que preserva a dignidade daquele que dedicou sua força de trabalho a determinada atividade empresária; ninguém se dedica mais à empresa do que seus sócios e empregados, e qualquer restrição a tal direito representa grave desvalorização do trabalho humano. FERNANDES (2011, p. 46)”.

Além disso, existe outra norma limitadora, qual seja o Art. $54^{6}$, IV da lei prevê que o devedor terá como prazo limite, no plano de recuperação judicial, 12 (doze) meses para o pagamento dos débitos trabalhistas, vencidos até a data do pedido de recuperação judicial. Ainda, no parágrafo único do mencionado artigo, inclui-se a limitação da verba salarial dos trabalhadores, devendo a empresa recuperanda promover o pagamento em até trinta dias das verbas estritamente salariais, vencidas nos três meses anteriores ao pedido de recuperação, observando o limite de 5 (cinco) salário mínimos por trabalhador.

Busca assim, o não exaurimento dos recursos da empresa que culminem a sua falência, mesmo que para isso imponha limites aos trabalhadores, tal limitação encontra-se amparada no princípio da preservação da empresa, o qual ao primeiro momento parece ser prejudicial ao trabalhador, mas num segundo momento, qual seja, a recuperação propriamente dita promove a manutenção dos postos de trabalho dos empregados ligados diretamente com a empresa, bem como daqueles ligados indiretamente através dos fornecedores e varejo.

\footnotetext{
6 Art. 54. O plano de recuperação judicial não poderá prever prazo superior a 1 (um) ano para pagamento dos créditos derivados da legislação do trabalho ou decorrentes de acidentes de trabalho vencidos até a data do pedido de recuperação judicial.

Parágrafo único. O plano não poderá, ainda, prever prazo superior a 30 (trinta) dias para o pagamento, até o limite de 5 (cinco) salários-mínimos por trabalhador, dos créditos de natureza estritamente salarial vencidos nos 3 (três) meses anteriores ao pedido de recuperação judicial.
} 
Fez por bem a Lei $\mathrm{n}^{\circ} 11.101$, de 09 de fevereiro de 2005, acompanhando as legislações ancestrais, conceder um tratamento diferenciado aos créditos de natureza trabalhista, em especial no tocante à preferência do recebimento das verbas salariais. (...) O caráter alimentar e humanístico se sobrepõe a qualquer tipo de crédito representativo de capital diverso do que retrata a contraprestação de trabalho realizados. DOMINGOS (2009, p. 85).

Cumpre ressaltar que o privilégio oriundo da classe trabalhadora acompanha o entendimento constitucional, o qual estabeleceu o direito dos Trabalhadores como integrantes dos Direitos Sociais, quiçá sobre a garantia do emprego como Direitos Fundamentais.

Assim, como o direito do trabalhador é constitucionalmente protegido, surge a primeira contenda sobre a possibilidade ou não de mitigação de direitos trabalhistas, principalmente relacionados com a redutibilidade salarial e limitação do direito de crédito em um processo judicial. Sobre o tema leciona SILVA (2003, p. 288-289) que:

O Art. $6^{\circ}$ define o trabalho como direito social, mas nem ele nem o Art. $7^{\circ}$ trazem norma expressa conferindo o direito ao trabalho. Este, porém, ressai do conjunto de normas da Constituição sobre o trabalho. Assim, no Art. $1^{\circ}$, IV, se declara que a Republica Federativa do Brasil tem como fundamento, entre outros, os valores sociais do trabalho; o Art. 170 estatui que a ordem econômica funda-se na valorização do trabalho, e o art. 193 dispõe que a ordem social tem como base o primado do Trabalho. Tudo isso tem o sentido de reconhecer o direito social ao trabalho, como condição da efetividade da existência digna (fim da ordem econômica) e, pois, da dignidade da pessoa humana, fundamento, também, da República Federativa do Brasil (Art. $1^{\circ}$, III). E aqui se encontram o direito individual ao livre exercício de qualquer trabalho, ofício ou profissão, com o direito social ao trabalho, que envolve o direito de acesso a uma profissão, à orientação e formação de profissionais, à livre escolha do trabalho, assim como o direito à relação de emprego.

Nessa linha de raciocínio, pode-se concluir que o Princípio da Proteção ao trabalhador encontra-se inserido no rol dos direitos Sociais, bem como vinculado aos próprios fundamentos da República Federativa do Brasil prevista no Art. $1^{\circ}$, III, da Constituição Federal.

Assim, justamente buscando a garantia do emprego ou, melhor a conservação da relação empregatícia contra a despedida arbitrária ante a falência da empresa, procura-se no instituto da Recuperação Judicial a manutenção dos postos de trabalho para que enfim o trabalhador possa continuar com o projeto de vida iniciado na aquisição de seu emprego, 
mesmo que para isso ao primeiro momento se pense em sua própria violação em cenários de crise. Continua SILVA (2003, p. 289) dizendo que:

Temos para nós que a garantia do emprego é um direito, por si bastante, nos termos da Constituição, ou seja, a norma do Art. $7^{\circ}$, I, é por si só suficiente para gerar o direito nela previsto. Em termos técnicos, é de aplicabilidade imediata, de sorte que a lei complementar apenas virá determinar os limites dessa aplicabilidade, com a definição dos elementos (despedida arbitrária e justa causa) que delimitem sua eficácia, inclusive pela possível conversão em indenização compensatória da garantia de permanência no emprego.

Desta maneira, superada a posição da garantia de emprego como norma constitucional, deve prevalecer a facilitação do instituto da Recuperação Judicial, eis que tem como finalidade precípua a manutenção da empresa bem como dos postos de Trabalho.

Nota-se, que se a finalidade buscada pelo constituinte ordinário esteve centrada na ideia da manutenção do emprego, o instituto da recuperação judicial, bem como os atos judiciais a ela correlatos devem seguir a mesma linha, ou seja, deve-se incentivar a promoção da recuperação e não facilitar a falência, limitando direitos sociais para tutelálos.

Consumindo o patrimônio de determinada sociedade empresarial, inexiste qualquer expectativa sobre a manutenção da garantia do emprego, tornando-se mais agressivo a falência da sociedade do que a frustração no direito de crédito dos credores num primeiro momento, justamente pelo fato que a existência da empresa promove a finalidade buscada no ordenamento jurídico como um todo, abastecendo a cadeia a ela relacionada, cumprindo sua função social em cenários de crise.

Assim, sendo a finalidade originária da lei de recuperações judiciais a promoção da manutenção das empresas, o poder judiciário na figura de estado juiz responsável pela análise do pedido de recuperação judicial, deve favorecer a promoção da continuidade empresarial e em nenhum momento facilitar apenas a satisfação do direito de crédito, promovendo como resultado a falência, pois indiretamente está violando o direito dos trabalhadores em cenários de crise.

Dentro da lei de recuperações judiciais, verifica-se a existência de alguns artigos que maculam essa finalidade almejada, como pode-se citar a condição impeditiva do Artigo 
191-A ${ }^{7}$ do CTN, o qual obriga a quitação prévia de todos os débitos tributários para que só assim, seja deferido o pedido de recuperação judicial.

Ao que parece o mencionado artigo não se encontra em consonância com o instituto da recuperação judicial, tanto isso é verdade que a jurisprudência dominante entende sobre a inaplicabilidade do mencionado artigo. Verifica-se que a aplicabilidade do artigo confronta com toda a lei e, além disso, torna a relação de limitação das verbas trabalhistas desarrazoada, pois permite-se a limitação da verba alimentar do trabalhador, mas não abriga a dívida tributária.

Desta forma, sendo uma das finalidades do direito do trabalho a promoção do combate ao desemprego, deve-se ter uma influência deste ramo do direito junto ao instituto da recuperação judicial, em especial quanto ao incentivo a continuidade da atividade empresarial e o combate da satisfação do direito de crédito de credores a qualquer custo de forma desordenada promovendo a falência empresarial.

Para que isso ocorra a doutrina e a jurisprudência tem entendido como válida e legal a limitação e mitigação de alguns princípios basilares do Direito do Trabalho, ao ponto que ela limita o trabalhador que detém crédito sobre uma empresa em recuperação judicial num primeiro momento receber apenas os últimos 3 (três) meses e, no limite de 05 (cinco) salários mínimos.

Porém, tal entendimento não é pacífico na doutrina, sendo que grande parte defende que o instituto da recuperação judicial visa suprimir direitos dos trabalhadores e favorecer as empresas que continuam com a sua atividade lucrativa. [...] Acontece, que, na recuperação judicial, os empregados mantidos em seus postos de trabalho não possuem nenhum garantia de emprego, podendo até mesmo ser reduzidos seus salário, mediante acordo coletivo FERNANDES (2011, p. 73):

\footnotetext{
${ }^{7}$ Art. 191-A. A concessão de recuperação judicial depende da apresentação da prova de quitação de todos os tributos, observado o disposto nos arts. 151, 205 e 206 desta Lei.
} 
Verifica-se, portanto, que o posicionamento não é uniforme tanto na doutrina quanto na jurisprudência. Porém, respeitadas as críticas, entende-se que em homenagem ao princípio da preservação da empresa, o resultado final almejado, por mais que implique em redução e limitação das verbas trabalhistas, parece ser mais adequado em cenários de crise do que aqueles previsto no antigo instituto da concordata que priorizava a decretação da falência. NASCIMENTO (2011, p. 71) comenta que:

O direito do trabalho é a expressão de humanismo jurídico e arma de renovação social pela sua total identificação com as necessidades e aspirações concretas do grupo social diante dos problemas decorrentes da questão social. Representa uma atitude de intervenção jurídica para a reestruturação das instituições sociais e para melhor relacionamento entre o homem que trabalha e aqueles para os quais o trabalho é destinado. Visa também a uma plataforma de direito básico do trabalhador, impostergáveis, como o direito a um salário, ao descanso diário, semanal e anual, à proteção da integridade física e saúde como reparação econômica dos danos que suportar pelo exercício do trabalho. O direito do trabalho é legítima manifestação da ordem jurídica voltada para o homem como a medida de todas as coisas.

Destaca-se ainda, que se pode incluir o Direito do Trabalhador como integrante do rol dos direito humanos, em especial sobre a proteção a dignidade da pessoa humana, condicionando o direito ao trabalho um meio de satisfação da finalidade moral atrelada a esse princípio.

Pode-se compreender que o direito do trabalho busca a valorização do humanismo jurídico em uma relação de trabalho, integrando o rol dos direito humanos. Ao certo, podese constatar que uma empresa em regime pré-falimentar que atrasa o pagamento dos salários de seus empregados encontra-se ferindo essa questão social, em especial o direito ao próprio salário do trabalhador.

Porém, diante desse embate de viés principiológico surge como trabalho aos doutrinadores e ao Poder Judiciário, sopesar qual bem jurídico deve ser mais tutelado, o direito ao salário ou o direito a manutenção do emprego, tentando ao máximo valorizar os dois no caso concreto. Em um cenário de avanço econômico é possível tutelar ambos, contudo, dentro do cenário de crise, a escolha é fundamental.

Como exposto anteriormente, essa tarefa tem difícil solução e a princípio deve ser encarado como exceção e não como regra, pois presume-se que a empresa nasceu para ter 
continuidade e não prazo determinado. Bem como o trabalhador foi contrato para receber todo o seu salário e desempenhar seu labor por um prazo indeterminado.

Assim, chocam-se os interesses dos empregados que ao primeiro momento buscam apenas a liquidação do seu crédito trabalhista, ao passo de toda a sociedade relacionada à empresa em regime pré-falimentar, que busca a manutenção de sua existência com a garantia dos postos de trabalho indiretamente relacionados.

Como meio de solucionar essa contenda, criada entre a garantia do trabalho e o direito do salário, deve o instituto da recuperação judicial buscar uma maneira em que o empregado salde seu direito de crédito e garanta a permanência dos postos de trabalho e a solvência dos demais credores.

Para isso, o plano de recuperação judicial deve cumprir sua função social, na medida em que durante o curso processual da recuperação todos os credores possam subsistir a essa situação de crise empresarial, mantendo os postos de trabalho diretos ou indiretamente ligados.

Nesta linha pode-se verificar que princípio da função social está intimamente ligado ao princípio da preservação da empresa, bem como o da proteção dos trabalhadores. Sobre isso DOMINGOS (2009, p. 80), comenta que:

A função social representa intrinsecamente o papel do empresário ou da sociedade empresária dentro da esfera social de um país, pois cria e faz circular emprego e renda, gera riquezas e influencia diretamente na vida cultural, social e econômica da nação. Contudo, como no princípio da preservação da empresa, o princípio em apreço se encontra, prima facie, nas mãos dos próprios credores que irão deliberar sobre o plano de recuperação judicial e posteriormente na discricionariedade do magistrado.

O princípio da função social não é peculiar apenas da empresa, mas sim de toda a nação, ele promove o equilíbrio contratual como se de um lado da relação jurídica estivesse presente toda a sociedade. Assim, devido ao fato que o processo de recuperação judicial abrange uma generalidade de indivíduos, deve-se, portanto, para manter o equilíbrio sócio econômico para que a empresa tenha condições para se recuperar, haja vista que durante o período economicamente favorável ela cumpriu sua função social. 
A Função Social nada mais é que uma forma de compatibilização e adequação dos interesses da empresa com os interesses da sociedade representados nesse momento pelos empregados, acionistas, consumidores, credores e empregados dos fornecedores e/ou comerciantes, manifestando a forma ideológica de exploração do capital trazida pela Constituição Federal.

Porém, mesmo utilizando o princípio da função social, não pode-se afastar a conclusão de que a situação do trabalhador no processo de recuperação judicial é muito mais prejudicial do que era em relação à concordata. Porém, partindo da premissa que a recuperação deve buscar a manutenção da empresa no mercado de trabalho e, que esse resultado é mais favorável a toda a sociedade dela dependente, os limites impostos aos trabalhadores podem, por mais inconstitucional que parece ser, justificarem o sacrifício por eles suportados para tutelá-los.

\section{3 - O PRINCÍPIO DA COOPERAÇÃO JUDICIAL NO NOVO CPC}

Pelo princípio da cooperação judicial, com regramento expresso no Novo CPC (art. $\left.6^{\circ}\right)$, todos os sujeitos do processo devem cooperar entre si para que se obtenha decisão de mérito justa e efetiva dentro de um tempo razoável.

O dispositivo brasileiro guarda semelhança com a redação disposta no artigo $7^{\circ}$ do Código de Processo Civil Português, o dispositivo lusitano direciona as partes a justa composição do litígio, destacando a grande importância dos participantes do processo (Magistrados, mandatários judiciais, partes) no deslinde do feito, quando da decisão final da causa pelo Juiz, em eventual composição amigável (PORTUGAL, 2013).

Inserido no postulado ético da boa-fé (art. $5^{\circ} \mathrm{NCPC}$ ), a cooperação como ideia principiológica demonstra em seu contexto não somente sob o enfoque de atuação do Judiciário na prestação de informações e das partes em atuar de acordo com a boa-fé: é preciso que haja reciprocidade entre todos aqueles que colaboram para o alcance do objetivo processual, nitidamente representado no texto legal pela expressão "entre si", de forma as partes colaborarem entre si, entre o Judiciário reciprocamente este em relação as partes (NERY JUNIOR, ANDRADEN NERY, 2015, p. 208). 
Trata-se de se estabelecer um modelo de processo cooperativo, não restringindo-se apenas a contribuição das partes na colaboração do correto desenvolvimento do processo. Vai muito além das partes, estendendo-se aos auxiliares da justiça, terceiros intervenientes, e, especialmente ao Juiz e Ministério Público, atuantes como judicante e fiscal da lei no processo (BUENO, 2015, p. 45).

Desta forma, a reciprocidade retratada pelo dispositivo legal é vista pela doutrina não somente entre interesse das partes para com o Judiciário e de seus auxiliares e intervenientes entre si (MEDINA, 2015, p. 50-51). Em que pese os interesses contrapostos das partes no processo, a cooperação não se caracteriza precisamente na colaboração entre as partes quanto ao argumento em litígio apresentado no processo, mas sim, o propósito de um processo dialético franco, de forma que as partes possam dialogar de maneira transparente e sincera.

Pela visão da atuação Juiz de forma cooperativa ao processo, Mitidiero (2007, p. 54-55) destaca a ideia de participação do órgão judicante de forma participativa, como forma valorativa de desenvolvimento processual, em respeito ao princípio constitucional do contraditório, sem olvidar ao diálogo judiciário de forma isonômica, atendendo atualmente, a necessidade de tratamento igualitário entre o Judiciário e as partes, modelo inserido como princípio infraconstitucional na disposição do Código de Processo Civil (art. $7^{\circ}$ ).

Como complemento, indispensável estabelecer a sistematização dos deveres processuais que decorrem do princípio da cooperação. Para Didier Jr. (2011, p. 221-222), é grande o esforço de sistematiza-los, classificando-os em deveres de esclarecimento, lealdade e proteção.

Para as partes, o dever de postular em Juízo com clareza e coerência, em não litigar de má-fé, observando o princípio da boa-fé processual além da preocupação em não causar danos a parte adversária (DIDIER JR, 2011). Ao órgão jurisdicional, além do dever de lealdade, o dever de esclarecimento, na busca em clarear as dúvidas das partes e de esclarecer os pronunciamentos judiciais (DOS SANTOS, 2011, p. 70), bem como o direito de consultar as partes sobre questão não discutida no processo, o que coaduna e impossibilidade de se proferir pronunciamento surpresa sem a ciência das partes, previsão legal disposta nos artigos 9 e 10 do Novo CPC (DIDIER, 2011, p. 222-223). 
Como forma de redução das desigualdades no processo civil, Dos Santos (2011, p. 69/72) acrescenta o dever de prevenção e o auxílio direto dos jurisdicionados. Pela prevenção o julgador tem a incumbência de utilizar como premissa, critérios para deixar as partes cientes de eventuais déficits das alegações e pleitos, a exemplo claro, a possibilidade de emenda a petição inicial (GREGER, 2012, p. 129). Em harmonia, o auxílio direto buscar no jurisdicionado, o dever de auxiliar as partes na superação de dificuldades que impeçam ônus e o exercício de direitos (DOS SANTOS, 2011).

Quanto as sanções ao descumprimento de tais deveres, entende-se pela doutrina na ausência do descumprimento, apenas destacando que o princípio da cooperação, como dito, é um desdobramento da boa-fé (NERY JUNIOR, ANDRADE NERY, 2015, p. 208). Discorda-se pelos comentários, onde seja direcionado a parte (art. 79 e ss. Do Novo CPC), seja na figura do Juiz (art. 143 do Novo CPC), existem sanções quanto ao descumprimento dos respectivos deveres, ou melhor dizendo, quando ofensa das partes ao princípio da cooperação.

Portanto, após as digressões necessárias acerca do princípio da cooperação, faze necessário trazer de forma delimitada a necessidade da cooperação, como forma de auxílio e colaboração dos jurisdicionados em diferentes Juízos e Instâncias, como forma de trazer a solução ao que ora se discute.

Nesta linha de raciocínio, é possível estabelecer uma ligação entre o Juízo universal do processo de falência ou de recuperação judicial, e o Juízo especializado trabalhista, como forma de atender uma relação harmônica entre os direitos trabalhistas do empregador (princípio da proteção) e o resguardo destes direitos no processo de falência e recuperação judicial.

Por fim reitera-se, não se quer em hipótese alguma no presente trabalho suprimir a ideia de proteção aos direitos trabalhistas, até porque considera-se um direito constitucional garantido, no entanto, do mesmo modo, o que se pretende é relativizar as formas e condições de pagamento destes direitos no processos de falência, como forma de atender ao princípio da função social da empresa, sob a justificativa da manutenção da atividades e principalmente, dos postos de trabalho. 


\section{DA COOPERAÇÃO NACIONAL: UM INSTRUMENTO CONGRUENTE PARA A EFETIVIDADE DO PROCESSO}

Pela solução da ponderação dos princípios supra descritos, de forma a trazer à tona a necessidade de manutenção da atividade empresarial, atingindo o fim social peculiar do instituto da recuperação judicial, vale ressaltar as inovações propostas pela lei 11.305 de 2015 que retratam a cooperação entre o Poder Judiciário, como forma de solução de conflitos.

Neste sentido, pela regra do artigo 67 do Código de Processo Civil em vigor, é dever dos Jurisdicionados a recíproca cooperação por meio de seus Magistrados e Servidores nas esferas estaduais, federais e especializadas em todas as instâncias e graus de jurisdição.

Em dispositivo contínuo, complementa que os Juízos poderão realizar pedidos de cooperação para a prática de qualquer ato processual (art. 68).

As atividades de cooperação entre os Juízos eram utilizadas pelo CPC de 1973 através das formalidades de expedição de carta precatória e carta de ordem (MEDINA, 2015, p. 141). Na atualidade, o Novo CPC, visando a efetividade do processo, com vias transformá-lo como instrumento apto a solução de conflitos (DINAMARCO, 2008, p. 25), demonstra a lógica de considerar os órgãos que compõem o Judiciário, não como instituições fechadas e separadas das demais, mas como órgãos que devam atuar de forma ordenada e cooperada configurando uma rede jurisdicional (MEDINA, 2015, p. 141).

Portanto, materializa-se nos dispositivos em comento, o princípio da cooperação como uma forma de unir os órgãos judiciais na tarefa de fazer do processo, uma "mão de via única”, de forma que os interesses opostos de juízos e jurisdicionados possam ser compartilhados a fim de que os conflitos de natureza especial e comum, por exemplo, convivam de forma harmônica e tenham a respectiva satisfação, pela contribuição do Poder Judiciário de maneira democrática, atendendo aos propósitos inclusive, de natureza constitucional.

A visualização do princípio da cooperação torna-se clarividente, quando se observa a prescrição legal do artigo 69 do Novo CPC, que demonstra a desnecessidade de formalidade específica para o respectivo pedido, com a execução via: a) auxílio direto; b) 
reunião ou apensamento de processos; c) prestação de informações; d) atos concertados entre os Juízes operantes.

Dentre as figuras de execução da cooperação entre jurisdicionados, destaca-se para o presente trabalho os atos concentrados entre os Juízes operantes. Isto porque, o $\S 2^{\circ}$ do artigo supra declara um rol enunciativo (MEDINA, 2015, p. 143) de atos harmônicos a serem praticados pelos Juízos, dentre os quais destacam-se: a efetivação de medidas e providências para recuperação e preservação de empresas (inciso IV). Ademais, corroborando a ideia de cooperação na manutenção das atividades empresariais, favorecendo a preservação da empregabilidade e atingindo o princípio da função social da empresa o $\S 3^{\circ}$ amplia a atuação da cooperação por órgãos de diferentes ramos do Poder Judiciário.

Logo, reflete-se a flexibilização de condutas aptas a atingir a colaboração dos jurisdicionados, por meio da harmonia de atuação entre os órgãos judicantes. E esta flexibilidade que torna a norma livre e ausente de desembaraços para efeito de alcance da efetividade no processo (WAMBIER [et al.], 2015, p. 136).

Este mesmo rol exemplificativo amplia especialmente a utilização de forma ampliada do $\S 3^{\circ}$ do artigo 69 quando de forma expressa, permite a utilização da cooperação judiciária de forma a integração de atividades entre diferentes órgãos do Poder Judiciário.

Em momentos de crise política, econômica e principalmente ideológica em razão dos reflexos da primeira e segunda hipótese, as atividades empresariais readéquam seus gastos financeiros, e o primeiro setor a ser atingido é o corpo colaborativo.

Tal procedimento prejudica de maneira direta os propósitos dos trabalhadores, com relação aos seus compromissos a médio e longo prazo, como é o caso dos empréstimos financeiros. E mais, altera a cadeia econômica das pessoas físicas e jurídicas vinculadas indiretamente aos reflexos negativos da quebra da lucratividade destes colaboradores.

Este caos econômico culmina nas inúmeras demandas trabalhistas com vias a obtenção da correlata tutela jurisdicional destes direitos dos trabalhadores. No entanto, indispensável que se estabeleça, uma relação entre a manutenção da atividade empresarial, dos postos de trabalho, e consequentemente, a manutenção deste corpo laborativo. 
Neste sentido, antes que se materializem várias dispensas, muitas delas arbitrárias, o que sujeita a um número considerável de processos judiciais, indispensável que se reorganize o correto adimplemento destas verbas de natureza trabalhista de maneira condicionada.

As consequências de inúmeras demandas trabalhistas, inviabilizará o direito de todos os trabalhadores, na quitação de suas verbas dentro da regularidade, e, ainda, provocará a consequência do término da atividade empresarial com a decretação da falência.

Portanto, pode-se estabelecer o princípio da cooperação, especialmente na correta aplicabilidade da cooperação nacional entre Juízos, de forma que o direito dos trabalhadores permaneça protegido, e do mesmo modo, a atividade empresarial cumpra o papel social de manutenção de postos de trabalho, em atendimento ao disposto ao art. 47 da lei 11.101 de 2005.

Note-se que os atos concertados de que trata o $\S 2^{\text {o }}$ do artigo 69 do Novo CPC guarda extrema relevância e objeto de fundamento do presente trabalho, quando se extrai a observância ao inciso IV, de se estabelecer procedimentos entre órgãos judicantes para a efetivação de medidas e providências para recuperação e preservação de empresas.

Relevante o fundamento legal como forma de justificar o que sustenta no presente. Isto porque, a manutenção de postos de trabalho, melhor dizendo, das atividades empresariais, é algo vital a subsistência do trabalhador, e vem de encontro ao princípio da proteção do trabalhador.

Propriamente a lei de recuperação de empresas e falência visa como objetivo anteriormente citado a manutenção das atividades empresariais, como forma de atingir o princípio da função social. Nisto, torna-se salutar por parte do empregado receber de forma reduzida ou parcelada seus haveres rescisórios, ou até mesmo as verbas contratuais não adimplidas de forma mediata, mas do mesmo modo, propiciar a correta manutenção da atividade empresarial.

No entanto, o papel fundamental do princípio da cooperação, especialmente na atividade da cooperação nacional, é a tendência da cooperação dos Juízos, especialmente o 
Juízo falimentar universal em total ato concertado com a Justiça especializada trabalhista, de forma que hajam medidas efetivas para a preservação da empresa.

Extirpar todos os recursos financeiros da empresa de forma imediata, para efeito do adimplemento das verbas de seus colaboradores, em eventual crise financeira, inviabilizaria de imediato a atividade empresarial. Neste sentido, indispensável que os órgãos judiciários se cooperem entre si, como forma de correta solução a salvaguarda de ambos os lados.

O diálogo proposto pelos órgãos jurisdicionais irá trazer em um momento de crise, a satisfação mediata, que a determinado prazo evitará o término das atividades empresariais. Com a ausência do diálogo positivo entre estes órgãos, por certo uma parte dos colaboradores se beneficiará com os créditos trabalhistas, no entanto, o esgotamento dos créditos da empresa culminará no fechamento da empresa, e o que é pior, no inadimplemento dos demais credores, além dos trabalhistas efetivamente.

Sendo assim, conclui-se que a ferramenta atribuída ao Novo CPC trouxe uma forma de minimizar os prejuízos oriundos da problemática econômica vivenciada momentaneamente. $\mathrm{O}$ desespero não soluciona o problema. Pelo contrário, apenas agrava as mazelas criadas pela crise econômica.

Neste sentido, é hora de repensar o modelo de unilateralidade e solução dos problemas litigiosos por apenas um órgão judicante, sem o diálogo das demais esferas. Há a necessidade preeminente do diálogo entre os órgãos do Poder Judiciário, como forma de colaborar para a solução satisfatória dos litígios, com o menor esforço atribuído as partes, inclusive como uma satisfação favorável dentro de um tempo razoável.

Com a observância a tais princípios elencados de forma expressa na Constituição Federal e hoje expressamente disciplinado no Novo CPC, as dificuldades empresariais ficarão minimizadas, se os atos concertados de Justiça de processo de falência/recuperação de empresas e Justiça do Trabalho andarem harmonicamente, de forma a albergar ambos os direitos (direito ao salário e direito a função social da empresa). 


\section{CONSIDERAÇÕES FINAIS}

Conforme já observado no estudo, está amplamente evidenciado que o real motivo pelo qual a Lei 11.101/2005 foi criada consiste no atendimento aos postulados do direito empresarial, enraizados nos princípios da preservação da empresa, função social da empresa, participação ativa dos credores e proteção do trabalhador.

Nota-se que existem no mencionado dispositivo legal, algumas cláusulas que suprimem e mitigam direitos dos trabalhadores, sendo que o tema não tem entendimento consolidado perante os doutrinadores de Direito Empresarial e Direito do Trabalho.

O presente trabalho conclui valorizando o instituto da Recuperação Judicial e o princípio da preservação da empresa, ao ponto que a decretação da falência, resultado que não se almeja, produz efeitos mais prejudiciais a sociedade e a classe operária ligada direta ou indiretamente, justificando assim essa possível limitação salarial imposta na Lei, como exceção e não regra em contextos de crise.

Conclui-se que o direito ao emprego faz parte do rol dos direitos humanos e fundamentos da República Federativa do Brasil e, neste passo devem ter tratamento privilegiado, portanto, por mais contraditório que pareça, em cenários de crise é possível mitigar direitos dos trabalhadores para tutelá-los.

A manutenção da empresa ocorre em virtude de que esta durante o período de exploração econômica cumpria sua função social, ou seja, explorava sua atividade dentro de uma política ideológica de exploração social do capital.

Fundamenta-se também, que a mitigação de alguns direitos trabalhistas tem como vetor único a manutenção da própria empresa para a continuidade no mercado de trabalho, para que assim possa solver seus créditos tanto trabalhistas como quirografários e, promover a manutenção dos postos de trabalho e do equilíbrio financeiro de toda a relação.

O Novo Código de Processo Civil vem ratificar essa ideia com o diálogo e a cooperação judiciária, portanto, o destaque trazido procura fundamentar processualmente a 
ideia de conciliar e dialogar o que no direito material aparenta ser inconciliável, tutelando o inverso para promover a eficácia dos direitos dos trabalhadores.

\section{REFERÊNCIAS}

BUENO, Cassio Scarpinella. Novo Código de Processo Civil Anotado. São Paulo: Saraiva, 2015.

BERTOLDI, Marcelo M., RIBEIRO, Marcia Carla Pereira. Curso Avançado de Direito Comercial. 3. Ed reformulada, atualizada e ampliada, Editora Revista dos Tribunais, 2006. $767 \mathrm{p}$.

DIDIER JR, Fredie. Os três modelos de direito processual: inquisitivo, dispositivo e cooperativo. Revista de Processo, São Paulo, ano 36, n. 198, p. 213-225.

DINAMARCO, Candido Rangel. A Instrumentalidade do Processo. 13 ed. rev. e atual. São Paulo: Malheiros Editores, 2008.

DOMINGOS, Carlos Eduardo Quadros. As Fases da Recuperação Judicial. 1. Ed São Paulo: Livraria do Advogado, 2009. 216 p.

DOS SANTOS, Igor Raatz. Processo, igualdade e colaboração: os deveres de esclarecimento, prevenção, consulta e auxílio como meio de redução das desigualdades no processo civil. Revista de Processo, São Paulo, ano 37, n. 206, p. 47-80.

FERNANDES, Claudia Al-Alam Elias. O Crédito Trabalhista e os limites que o direito do trabalho impõe ao plano de recuperação Judicial. Dissertação de mestrado apresentada em 2011, Faculdade de Direito da USP - Disponível em www.teses.usp.br/teses/.../Claudia_Al_Alam_Elias_Fernandes.pdf. acesso em 08 abr. 2016.

GREGER, Reinhard. Cooperação como princípio processual. Traduzido por Ronaldo Kochem. Revista de Processo, São Paulo, ano 37, n. 206, p. 213-225, p.123-133. MARTINS. Sergio Pinto. Direito do Trabalho. 21 Ed - São Paulo: Atlas, 2005. 895 p. 
NASCIMENTO, Amauri Mascaro. Iniciação ao Direito do Trabalho. 36.Ed - São Paulo, LTr, 2011. 588p.

NERY JUNIOR, Nelson; DE ANDRADE NERY, Rosa Maria. Comentários ao Código de Processo Civil. São Paulo: Editora Revista dos Tribunais, 2015.

PORTUGAl. Código de Processo Civil Português. Lei n. ${ }^{\circ}$ 41/2013, de 26 de junho, retificada pela Declaração de Retificação n. ${ }^{\circ}$ 36/2013, de 12 de agosto - Aprova o Código de Processo Civil (revoga o Decreto-Lei n. ${ }^{\circ} 44129$, de 28 de dezembro de 1961 / em vigor a partir de 1 de setembro de 2013). Disponível em: http://www.dgpj.mj.pt/sections/leis-da-justica/livro-iii-leis-civis-e/leis-de-processocivil/codigo-de-processo-civil. Acesso em 07 abr. 2016.

SILVA, José Afonso da. Curso de Direito Constitucional Positivo. 22 Ed - São Paulo: Malheiros, 2003. 878 p.

MEDINA, José Miguel Garcia. Novo Código de Processo Civil Comentado: com remissões e notas comparativas ao CPC 1973. São Paulo: Editora Revista dos Tribunais, 2015.

MITIDIERO, Daniel. Bases para a construção de um processo civil cooperativo o direito processual civil no marco teórico do formalismo valorativo. 2007. $147 \mathrm{f}$. Tese (Doutorado em Direito) - Faculdade de Direito, Universidade Federal do Rio Grande do Sul, Porto Alegre. 2007.2 Disponível em: https://www.lume.ufrgs.br/bitstream/handle/10183/13221/000642773.pdf?sequence=1. Acesso em 07 Abr. 2016.

WAMBIER, Teresa Arruda Alvim (et. al.). Primeiros Comentários ao Novo Código de Processo Civil: artigo por artigo. 1. ed. São Paulo: Editora Revista dos Tribunais, 2015. 